\title{
IDENTIFICATION OF FORMS AND COMPONENTS OF VO INHERITANCE
}

Iris Karvonen, Iiro Salkari, Martin Ollus

VTT Industrial Systems, FINLAND

Iris.Karvonen@vtt.fi, Iiro.Salkari@vtt.fi, Martin.Ollus@vtt.fi

\begin{abstract}
Virtual Organizations (VO) are created from a VO Breeding Environment (VBE) or a network, to serve a specific task. In addition to the task-based value the $V O$ and its participants gain valuable experience and create other types of assets. Most often this achieved value is not saved. It is distributed, not managed and sometimes not even identified. The practise of preserving and reusing the common experience and other non-proprietary assets created in the $V O$ is called here "VO inheritance". VO inheritance aims to enrich the VBE "bag of assets", thus improving the preparedness of the VBE for business opportunities. The added value, or the contents of the VO inheritance, is called here "VO heritage".The paper identifies different forms and components of VO heritage. The identification uses previous development of "lessons learnt" in project management field, and a collection of views of SMEs operating in collaborative networks.
\end{abstract}

\section{INTRODUCTION}

The concept of Virtual Organization Breeding Environment (VBE) (Camarinha-Matos et al., 2005) aims to establish sustainability and continuity in the environment of one-off or temporary customer deliveries (Virtual Organizations, VOs). Even if the operation as discontinuous VOs may increase flexibility, agility and resource utilization efficiency, it also causes challenges (Karvonen et al. 2004), for example risk of losses of information, knowledge or other values. VO inheritance, defined here as "the practice of storing and passing on the experience and other non-proprietary assets created through collaboration in a VO" (ECOLEAD D33.1 2006)) aims to strengthen the VBE by preserving the common valuable outcome ("VO heritage") from VOs to the VBE. Currently in operating networks a systematic management of $\mathrm{VO}$ inheritance is most often missing.

Often VO inheritance is mainly understood as the task of transferring the VO performance history to the VBE. Even if the VO Performance Historical Repository, including both the VO performance models and the related historical data is an important part of VO heritage (ECOLEAD D31.2, 2005), it also includes other types of valuable components which need concern.

In the Project Management field (PMBOK 1996) the inheritance is handled through the activity of "lessons learned" in the project closing phase. Schindler and Eppler (2003) view the learning from project experiences through two groups of methods: process-based methods and documentation-based methods. Also in some specific fields of projects the re-use of information has been discussed, like for engineering projects (Fiatech 2001). These approaches focus on data, information and knowledge, not on other types of assets.

The first step for the systematic preservation of VO heritage is to identify the valuable outcomes to be saved. This is the focus in this paper. The study has been supported by collecting experience, needs as well as priorization of different types of VO heritage from industrial end-users (SME networks).

Karvonen, I., Salkari, I., Ollus, M., 2007, in IFIP International Federation for Information Processing, Volume 243, Establishing the Foundation of Collaborative Networks; eds. Camarinha-Matos, L., Afsarmancsh, H., Novais, P., Analide, C.; (Boston: Springer), pp. 253-262. 
The main definitions and objectives of VO inheritance are described in chapter 2. Chapter 3 describes and discusses the main types of VO heritage. The results of the SME network query are summarized in chapter 4 and chapter 5 gives challenges and further development needs.

\section{OBJECTIVES OF VO INHERITANCE}

\subsection{Definitions}

Wikipedia (www.wikipedia.org 2007) gives a definition of inheritance of an individual:

"Inheritance is the practise of passing on property, titles, debts and obligations upon the death of an individual."

This definition has been used and adapted to create a first definition of VO inheritance:

"VO inheritance is the practice of storing and passing on the experience and other non-proprietary assets created through collaboration in a VO."

The definition has not been settled yet. Thus VO inheritance is often also used to describe the contents of VO inheritance, that is, what is inherited. In this paper, a specific concept of VO heritage is used:

"VO heritage comprises of the different assets which are inherited from a VO to the VBE."

The VO product/service going to the customer will be the property of the customer after the VO dissolution and is thus not part of VO heritage. That is why the object of inheritance (what is inherited) excludes the assets which belong exclusively to only one partner. Assets with restricted IPR are usually not considered as part of the VO heritage. This does not, however, imply, that all the VO heritage is open for all VBE members.

Management of VO inheritance knowledge and information can be considered as a specific case of Knowledge Management, but VO inheritance management is not only about managing knowledge or information, but also of other types of assets. Thus VO inheritance is not only Knowledge Management.

The given definition refers to assets created in a VO. In general an asset is something that has future value: it can be used to create value. Assets can be both tangible and intangible.

In ECOLEAD D21.4a (ECOLEAD 2006) a concept of "VBE bag of assets" is defined: "The VBE Bag of Assets refers to all valuable elements that different VBE Members may wish to share with others and which are available to all VBE members."

\subsection{Benefits of $\mathrm{VO}$ inheritance}

The objective of a VO is either to perform a specific task or to create a specific product/ service to a customer in an inter-organizational environment. The main focus of VO management is to achieve this goal (ECOLEAD D32.1, 2005). If the need for the VOs is repetitive with sufficient frequency, it is beneficial to develop preparedness by creating a Virtual organization breeding environment (network) 
(VBE): developing processes, systems, rules and practices which support the collaborative tasks.

When there is a need for a collaborative task, for example a customer request, a $\mathrm{VO}$ is created from a VBE for the delivery. After the completion of the task the VO is dissolved and the increased knowledge, experience and other useful outcome should be returned, "inherited" to the VBE (network). Each organization may utilize these assets individually but in addition they can be used to improve the preparedness of the VBE (network). Further, if the VO has been successful, the references and reputation created can be used externally to convince the customers.

Thus VO inheritance is aimed to increase the "bag of assets" of the VBE (ECOLEAD D21.4a, 2006). This benefit may be realized through:

- - improving the preparedness of the VBE: VOs can be created and started faster,

- - making the VOs more effective and reliable both in time and costs, and improving or ensuring the quality,

- - decreasing VO management efforts through increased trust and strengthened relationships,

- - supporting decision-making and tracking of VO problems or deviations,

- - increasing the value of the VBE for the members, for example by increaseing their knowledge and market position,

- - supporting winning in competitive bidding because of customer knowledge and closer customer relationships,

- - supporting the marketing of the VBE services to new customers by offering references of past deliveries.

\subsection{Inheritance as the enabler for the VBE feedback loop}

In ECOLEAD D32.1 (ECOLEAD 2005) approaches to describe different characteristics of VBEs/networks and virtual organizations have been reviewed. The Globeman21 approach (Pedersen et al., 1999, Zwegers et al. 2003) identifies two kinds of descriptive parameters: Situational factors are environment conditions which cannot be changed or selected, and design parameters are selected parameters.

Virtual Organization Breeding Environment (VBE) and VO have both their own, interdependent descriptive parameters. When a VO is created from a VBE, the characteristics of the VBE (both the situational and design factors of the VBE) are situational factors for the VO. The VO design factors may be decided at the VO creation.

On the other hand, the inherited experience gained in VOs gives back information to the VBE. The VO experience may affect the BE design parameters and be useful in the evolving process of the VBE (Figure 1, Karvonen et al. 2005). As the VBE design parameters are situational factors for the VO, the inheritance enables the effect of VO experience to the preconditions of VOs (VBE). This can further contribute to the success of the VOs. Currently this feedback loop is usually not working. 


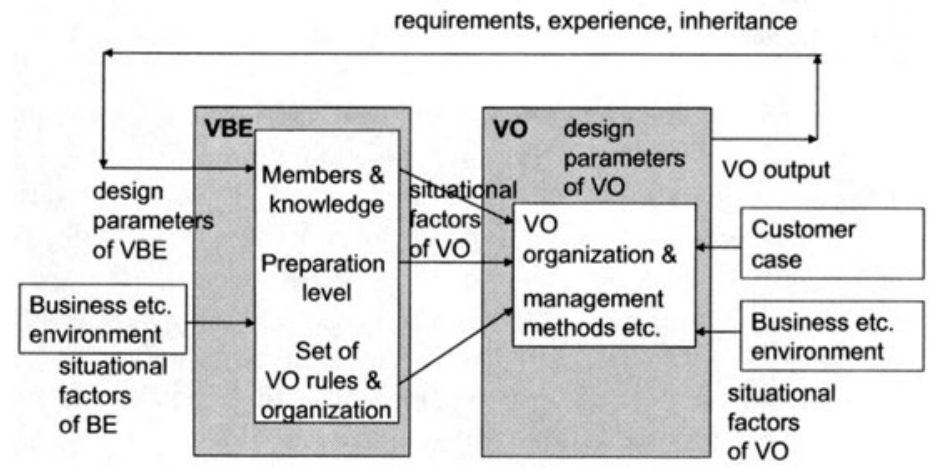

Figure 1. Feedback from VO output to BE design.

\section{COMPONENTS OF VO HERITAGE}

\subsection{Different forms of assets}

VO inheritance increases the common VBE Bag of Assets. These assets are not as concrete and visible as the product created to the customer, and thus often the VBE does not even become aware of their existence. To identify the different forms of VO heritage the categorisation of VBE bag of assets can be used. ECOLEAD D21.4a (ECOLEAD 2006) identifies three main types of assets:

1. financial capital: financial resources and values (cash, accounts, physical assets), risky elements

2. intellectual capital: data, information and knowledge, both in tangible and intangible (human) form

3. social capital: also called relational assets; relationships with customers, suppliers and other organizations.

\subsection{Inheriting financial capital}

Financial capital is typically owned by the independent organizations. However, in principle it is possible that part of the profit created in a VO would be inherited to the VBE. This could be used to pay for the common infrastructure services, development of common procedures and possibly as a reserve fund to reimburse expenses of potential customer complaints.

When discussing inheritance, an important point to solve is also how to take care about the potential risky or negative outcome of the VO:

4. Warranties of the customer product

5. Other obligations and liabilities

6. Inheritance of failed VOs, realized risks

These post-VO liabilities may cause financial expenses and may thus be considered as negative financial heritage. They may require additional work, resources or costs, cause a delay of the customer payment, or decrease the payment.

\subsection{Intellectual capital: information assets}

The intellectual capital includes all the VO data, information and knowledge, both in databases and documents and in human minds. The information may be both plans 
and experience about their realization, both of quantitative (for example performance measures) and qualitative type. As it is easier to collect and save quantitative data, in many cases there is a lack of restored qualitative information; for example of reasons behind decisions.

The categorization of knowledge in project management field has been analysed by for example van Donk et al. (2005). He has ended up with a categorization that defines three knowledge aspects of project-based organizations:

7. Entrepreneurial knowledge, which is restricted to project acquisition from markets.

8. Technical knowledge that focuses tightly to technological questions from technological viewpoints.

9. Project management knowledge, which combines aspects of project management know-how and experiences in conducting and managing projects.

In the context of VOs the accumulated entrepreneurial knowledge includes understanding the market conditions, customers' business and value creation to the customers.

Technical knowledge, including the product design and technological solutions, is needed and produced during VO sales, creation and execution phases. The level of detail of the technical knowledge increases along these phases.

Project (or VO) management knowledge is needed and accumulates from sales onwards, through VO planning, execution, monitoring, evolution and dissolution. The VO management knowledge consists of VO management process knowledge, planning and monitoring levels and techniques, partner performances, and knowledge concerning soft issues like trust.

One specific challenge is to manage IPR in collaborative relationships. In most cases IPR belongs to a specific organization, but there may be cases when the VO creates IPR which cannot be considered as the property of one organization. Even if IPR is currently often not considered as part of VO heritage the VBE should define rules how to handle the issue.

\subsection{Social/relationship capital}

Social/relational VO heritage is nearly linked to the increased knowledge of the collaborating organizations. However, the relational assets do not consist of the knowledge, but of the relationships. It is clear that having even all the knowledge about the relationship has not the same value as having the "living" relationship.

Social and relational capital originates from collaboration. Thus VOs, where the partners collaborate for a common objective, are important contributors to the VBE social capital. Two different types of VO relational inheritance can be distinguished:

1. The increase of relational capital between the VBE members: Operating in a VO makes the partners to know each other better both at the personal and organizational level. This means that they know the capabilities, strengths and weaknesses of each other, which makes it more effective to collaborate in the future VOs, and increases the VBE preparedness. VOs also produce tested configurations of partners for specific tasks. Collaboration increases the trust between the partners and contributes to the creation of a VBE "culture". Especially successful VOs increase the motivation of partners to work together. 
2. The increase of relational capital with the customers: Working with the customers contributes to improved customer relationship and understanding the customer needs which is very useful for future business and identification of new business opportunities. Also improved personal relationships and knowledge of customer practices support the preparedness to work for the customer in future. Successful VO deliveries to the customer increase the customer's trust to the VBE. The achieved market position and the references may also be considered as part of $\mathrm{VO}$ relational heritage and they are typically very important in order to gain also new customers.

Collaboration is not always successful and all the social relationships do not improve in every VO. It is even possible, that the overall social VO heritage is sometimes negative. In some cases it may even danger the sustainability of the VBE. Thus also mechanisms how to handle these cases, disagreements and disputes need to be considered.

\section{VIEWS OF SME NETWORKS OF VO INHERITANCE}

\subsection{Current practices}

To identify the practical needs, opinions and existing practices of VO inheritance a questionnaire was set up for a group of SME networks. The answers were received from eight networks located in different European countries.

All the involved networks identified a need for VO inheritance but they had very few implemented practices to deal with it and no actions planned. Most of the organizations had no practices for systematic collection and saving of experience, but some of them had informal, verbal exchange of experience between managers of similar VOs.

Some partners measured VO performance during the VO for the use of VO management. In some cases the customer required the recording of, for example, quality data. Long-term measurement of partner performance was exceptional. The collection of information from the network was considered difficult, for example, periodic textual questionnaires had not been successful.

Most of the networks had some kind of a platform/portal/server to manage information, but its usability was not always good and in some cases it was only used by the VO manager. Experiences were shared in the networks most often through different events: "cooperation meetings", working groups, discussion forums, workshops, seminars, exhibitions, training programmes, board meetings and round tables with partly business and partly social character. These can be used to share experiences, to introduce new members, present latest news and also to discuss ideas for development.

Mainly the networks had a similar practice for carrying responsibilities after the VO dissolution: the obligations towards the customer are typically carried by one company, which is the company managing the VO. Some of the respondents considered that the customer will never accept a shared responsibility. In some specific cases the risk sharing was defined in the contract, in a MOU (memory of understanding) or in a SLA (service level agreement). In one case it was mentioned that all the VO partners are included in a liability insurance which is placed by the VO manager. 


\subsection{VO experience: Importance and contents}

VO experience, including the information and (also tacit) knowledge is an important part of VO inheritance. The SME networks were asked to estimate the importance of VO experience for different parties operating in collaborative networks:

Most of the networks considered that VO experience is important for all parties, and that most important it is for the partner managing the VO. Customers were seen nearly as important users of the VO heritage. Towards the customer, VO experience gives references and credibility, and thus it can be used as a marketing tool and supporting new business opportunities.

The networks were asked to put the different contents of VO experiences in the order of importance by selecting between experiences of product knowledge, customer relationships and practices, process \& management knowledge (needed tasks, actions, resources, schedules, used approaches, templates etc.), faced changes and problems and how they were solved and partners and their performance.

While there are many development actions to collect experience about partner performance, it was interesting to see that the most important experience from the end user point of view was the experience about the customer. Also the process and management experience was nearly as important. The other three types were ranked less important. This may come from the fact that for many networks the main concern is the uncertainty of future business opportunities, inadequacy of customer orders and the instability of business.

The networks were also asked to describe the main contents of each type of experience. The results are reported in ECOLEAD D33.1 (ECOLEAD 2006).

\subsection{Other inheritance components}

Data, information and (even tacit) knowledge and experience are not all that can be cumulated via VOs. The networks were asked to identify the additional forms of inheritance by setting questions like:

10. -What does a VO/VT give to the participants (except experience and the order \& payment)?

11. -How does the state of the VBE differ before and after a VO?

12. - How does a VO affect the social/ relational capital?

13. -What is the effect to customer relationships?

14. -What about obligations and warranties?

For the first question the most commonly identified benefit was that fulfilled VOs contribute to new business opportunities, often also for more extensive responsibilities in the customer delivery. The experience of the fulfilled VOs may influence the strategy of the VBE members, as they learn to know better the resources and competences of other companies of the VBE. Also fulfilled VOs affect updating technology roadmaps and contribute to the creation of new ideas for collaboration.

The state difference of a VBE caused by a fulfilled VO depends on the development stage of the VBE: In a newly created VBE with little experience on collaboration the effect is stronger than in a mature VBE. In a developing VBE starting a VO may "heat up" the whole VBE. In the end, the respondents considered that fulfilled VOs define the quality of the VBE: "the number and size of VOs are the most important performance figures of a VBE". 
All the networks thought that successful VOs have the most positive effect to the social capital of the VBE. Fulfilled VOs contribute to trust building, motivation and commitment. The social capital is often dependent on personal relationships. It increases slowly and especial care is needed with partners with similar roles. Also, failed VOs may disturb the collaboration in future, thus, to avoid the negative effects a VO needs to have a certain level of trust before its creation.

Customer relationships are a special form of relational capital. Fulfilled VOs were typically seen as very strong instruments to improve the customer relationships. They contribute to the understanding of customer's future needs, customer's processes, behaviour and price building practices, create and strengthen personal contacts. Typically the customers operate via the interface of a specific company (broker or VO manager), which considers the customer as "their" relation and don't want to share it with the whole network. Thus, to avoid conflicts, the VBE should define rules and practices for customer relationship management.

Most of the customers of the networks do not seem to accept shared responsibility, and they expect that one organization takes the responsibility. Typically this is the VO manager or the one with the biggest share or closest ties to the customer. The VO/VBE may then define how it internally handles the responsibilities. The rules may be different for different responsibilities, like for on time delivery, warranties or other obligations. In collaborative innovation/research projects there is a risk of not obtaining the results, and the rules how to handle the realization of this risk need to be defined.

\subsection{Requirements from SME networks}

SME networks were also queried about their requirements for VO inheritance. The following are comments from the end-user networks:

1. Contribution to VO inheritance should appear rewarding and beneficial for the actors.

2. The contributions required from VO participants should be made as easy and short as possible. No overloading with sophisticated and laborious procedures will be accepted. Only necessary and really useful information should be saved and shared.

3. Part of the needed data could be created automatically or semi-automatically from the VO monitoring and operation. Collection of VO experience should partly happen as part of the VO management tasks.

4. Templates should be created to capture knowledge in order to allow categorization of information, and facilitate the search based on taxonomy. On the other hand, a sophisticated structure is not as important as easy search.

5. The information has to be easily accessible for all different users.

6. In some cases the amount of data may be a problem for its use, but in most cases the capture is the main problem.

7. Openness of the information is a complex question. In most cases it is unrealistic to have totally "open books". The right level of openness and transparency should be found.

All networks are not homogeneous; especially when they are in a growing phase. Part of the companies have more experience than the others and don't 
need all that information which again may be necessary for newcomers of the network.

\section{CONCLUSIONS AND CHALLENGES}

\subsection{Conclusions}

When developing mechanisms to accomplish VO inheritance the first step is to identify its different components and forms. The initial assumption was that the VO inheritance is mainly about storing and re-using the VO and partner performance models and values. The analysis of the VBE assets and end-user views, however, disclosed three specific aspects:

1. Social capital/relational assets are an important part of VO heritage. It is not about the information of the relationships but the relationships themselves. Thus it cannot be stored and treated with only ICT.

2. The relationships to the customers and the information about the customers were considered more important than the relationships to the VBE members. This might be affected by the fact that many of the end-user companies participating in the query operated in a broker role in the network. Management of customer relationship capital has additional unsolved challenges in non-hierarchical networks.

3. The VO heritage is always not only positive. The relational VO heritage may be negative, even in case of a successful VO. (On the other hand, the intellectual capital (experience knowledge) may increase also in an unsuccessful VO.)

VO inheritance aims to bridge the gap between the impermanent VOs. Transforming the VO discontinuity to continuous learning and improvement in the VBE is not an easy task. It requires attention both at the VBE and VO level. In VBEs the rules for the inheritance must be agreed: who is inheriting what, what are the user rights and information openness levels and responsibilities for the inheritance management. How to take care that the inherited information does not cause misuse or decrease of trust? How to refine the gained information for maximum benefit? At the VO level the main thing is to make the inheritance happen and to find inheritance mechanisms which don't require too many resources. In both forms methods and tools to identify the important information or to drag out knowledge from a mass of data or information should be developed. Also best practices to preserve the relational and structural assets of VOs should be found and implemented.

\subsection{Acknowledgments}

The paper is mainly based on work performed in the Integrated project ECOLEAD funded by the European Community under the Framework programme 6 (IP 506958). 


\section{REFERENCES}

1. Camarinha-Matos, L., Afsarmanesh, H., Ollus, M., 2005. ECOLEAD: A holistic approach to creation and management of dynamic virtual organizations. In Camarinha-Matos, L., Afsarmanesh, H. \& Ortiz, A. (Ed.), Collaborative Networks and Their Breeding Environments (pp 3-16). Springer.

2. ECOLEAD (EU/FP6 IP 506958) D31.2 VO Performance Measurement approach, performance metrics and measurement process, September 2005. www.ecolead.org.

3. ECOLEAD (EU/FP6 IP 506958) D33.1 VO inheritance components and mechanisms, September 2006. www.ecolead.org.

4. ECOLEAD (EU/FP6 IP 506958) D32.1 Challenges in Virtual Organisations Management., www.ecolead.org. March 2005.

5. ECOLEAD (EU/FP6 IP 506958) D21.4a Characterization of VBE Value Systems and Metrics, www.ecolead.org March 2006.

6. FIATECH (2001). Guidelines and Drivers for Achieving Plant Lifecycle Data Management. The owner - operator forum. January 2001. http://www.fiatech.org.

7. Karvonen, I., Jansson, K., Salkari, I., Ollus, M. (2004). Challenges in the management of virtual organizations. In Camarinha-Matos, L. (Ed.), Virtual Enterprises and Collaborative networks (pp 255-264). Kluwer Academic Publishers.

8. Karvonen, I.; Salkari, I.; Ollus, M. (2005). Characterizing Virtual Organization and Their Management. In Camarinha-Matos, L., Afsarmanesh, H. \& Ortiz, A. (Ed.), Collaborative Networks and Their Breeding Environment (pp 193- 204). Springer.

9. Pedersen, J.D., Tolle, M. Vesterager, J. Final report on Models. Deliverable 1.3 of Esprit 26509 Globeman 21 project. 1999.

10. PMBOK, 1996. A Guide to the Project Management Body of Knowledge. Project Management Institute Standards Committee. 1996.

11. Schindler M., Eppler M., 2003. Harvesting project knowledge: a review of project learning methods and success factors. International Journal of Project Management 21 (2003), pp 219-228. Elsevier Science Ltd and IPMA.

12. van Donk D., Riezebos J., 2005. Exploring the knowledge inventory in project-based organizations: a case study. International Journal of Project Management 23 (2005), pp 75-83. Elsevier Science Ltd and IPMA

13. WIKIPEDIA: http://www.wikipedia.org, reviewed 28.2.2007

14. Zwegers, A., Tolle, M, Vesterager J. VERAM: Virtual Enterprise Reference Architecture and Methodology., in Karvonen et al. Global Engineering and Manufacturing in Enterprise Networks (GLOBEMEN), VTT Symposium 224, 2003, p. 17-38. 